\title{
PROPRIEDADES FÍSICAS DE UM CAMBISSOLO HÚMICO ÁLICO AFETADAS PELO MANEJO DO SOLO
}

\author{
PHYSICAL PROPERTIES OF AN HAPLUMBREPTS AS \\ AFFECTED BY SOIL MANAGEMENT
}

\author{
Ildegardis Bertol ${ }^{1}$ Jefferson Schick $^{2}$ Jarmum Marcelos Massariol $^{3}$ \\ Émerson Fábio dos Reis ${ }^{3}$ Leonir Dily
}

RESUMO

A degradação física do solo é um dos principais processos responsáveis pelo aumento da erosão hídrica. Os preparos convencionais normalmente são aceleradores desse processo, pois a sua execução exige um intenso revolvimento mecânico do solo. Assim, a semeadura direta apresenta-se como um manejo conservacionista, pois a ausência de preparo preserva os resíduos culturais e aumenta a matéria orgânica, apesar de aumentar a densidade e diminuir a porosidade superficial do solo. O trabalho foi desenvolvido num cambissolo húmico álico, no Centro de Ciências Agroveterinárias de Lages - SC, no período de maio de 1995 a novembro de 1997. Os tratamentos de preparo do solo, preparo convencional executado com uma aração+duas gradagens, e semeadura direta sem revolvimento do solo, foram instalados em quatro repetições. Na semeadura direta, foram cultivadas aveia, milho, aveia, milho e aveia $e$, no preparo convencional, aveia, milho, pousio, milho e pousio, em seqüência. Foram avaliadas a densidade do solo, carbono orgânico, macroporosidade, microporosidade, porosidade total $e$ relação macroporos/porosidade total, nas camadas $0-2,5,2,5$ 5,0, 5,0-10,0 e 10,0-15,0 cm de profundidade. Nas camadas de 02,5 e 2,5 a 5,0cm, a semeadura direta apresentou maior densidade do solo e conseqüente menores macroporosidade e relação macroporos/porosidade total do que o preparo convencional. $\mathrm{Na}$ semeadura direta, a densidade do solo diminuiu com a profundidade, com conseqüente aumento na macroporosidade e na relação macroporos/porosidade total, enquanto no preparo convencional este comportamento foi inverso.

Palavras-chave: densidade do solo, porosidade do solo, carbono orgânico, estrutura do solo.

\section{SUMMARY}

Soil physical degradation is one of the main factors responsible for water erosion. The conventional tillage usually acellerates this process because it involves an intense soil tillage. Thus, no-tillage is considered a soil conservation management system because it preserves crop residue on the soil surface, inducing soil organic matter increase. However, no-tillage may also increase soil density and decrease surface soil total porosity. This study was conducted in Lages, SC, Brazil, on a Haplumbrepts soil, from May 1995 to November 1997. Two soil tillage treatments were used: conventional tillage (plowing plus disking) and no-tillage. Each soil treatment was replicated four times. The crop sequences used were oat, maize, oat, maize and oat in no-tillage system and oat, maize, fallow, maize and fallow in conventional tillage system. Soil bulk density, organic carbon, macroporosity, microporosity, total porosity and the ratio between macroporosity and total porosity were evaluated at soil layers of 0-2.5, 2.5-5.0, 5.0-10.0 and 10.0-15.0cm depth. Under no-tillage, there were higher values of soil bulk density and lower values of macroporosity and the ratio macroporosity/total porosity at the superficial layers of $0-2.5$ and $2.5-5.0 \mathrm{~cm}$. Conversely, soil bulk density decreased with depth in the notillage treatment, thus enhancing macroporosity and the ratio between macroporosity and total porosity at the deeper layers of soil profile. An opposite trend was observed for the conventional tillage.

Key words: bulk density, porosity, organic carbon, soil structure.

\section{INTRODUÇÃO}

O sistema de manejo convencional normalmente ocasiona degradação do solo pela perda da qualidade estrutural e aumento da erosão hídrica, especialmente quando dissociado de práticas conservacionistas. A semeadura direta constitui-se, assim, numa alternativa de manejo capaz de preservar as

\footnotetext{
${ }^{1}$ Engenheiro Agrônomo, Doutor, Professor da Faculdade de Agronomia, Centro de Ciências Agroveterinárias, Universidade do Estado de Santa Catarina, CAV/UDESC. Pesquisador do CNPq. CP 281, 88520-000, Lages, SC. E-mail: a2ib@cav.udesc.br. Autor para correspondência.

${ }^{2}$ Engenheiro Agrônomo, mestrando do Curso de Pós-graduação em Agronomia do CAV/UDESC. Lages, SC.

${ }^{3}$ Aluno da Faculdade de Agronomia do CAV/UDESC, bolsista de iniciação científica.

Recebido para publicação em 21.10.98. Aprovado em 28.04.99
} 
propriedades físicas e a capacidade produtiva do solo (SILVA \& MIELNICKZUK, 1997) e reduzir as perdas por erosão hídrica (BERTOL et al., 1997b). No entanto, ainda não está bem compreendido o comportamento de algumas propriedades físicas do solo nesse sistema de manejo.

O preparo, uma das principais operações de manejo do solo, objetiva modificar a estrutura, erradicar plantas daninhas e manejar resíduos culturais, aumentando a porosidade total na camada preparada (BURWELL $\boldsymbol{e t} \boldsymbol{a l}$., 1966). No entanto, seu principal efeito geralmente é refletido na perda da qualidade estrutural do solo (CARPENEDO \& MIELNICKZUK， 1990; SILVA \& MIELNICKZUK, 1997). Isso ocorre porque, na maioria das vezes, o preparo é executado com excessiva intensidade e sobre o solo em condições inadequadas de umidade, o que justifica sua redução e, se possível, a completa eliminação. Nos preparos conservacionistas, especialmente a semeadura direta, o não revolvimento do solo acarreta a consolidação da superfície em alguns tipos de solo.

O grau de consolidação da superfície é um dos processos que necessita ser melhor estudado, pois o seu comportamento varia com os tipos de solo e cultivo e com o tempo de condução do sistema (FERNANDES et al., 1983; VIEIRA, 1985; ELTZ et al., 1989). A densidade normalmente é maior na camada superficial, causada pelo não revolvimento do solo e pressão mecânica exercida pelo trânsito de máquinas e equipamentos (FERNANDES $\boldsymbol{e t}$ al., 1983; VIEIRA, 1985). No entanto, em alguns tipos de solo e/ou sistemas de manejo, esses valores podem não diferir com a profundidade (ELTZ et al. 1989) ou apresentarem valores maiores na subsuperfície do que na superfície.

$\mathrm{O}$ adensamento do solo acarreta diminuição da macroporosidade e porosidade total, o que implica em aumento da resistência à penetração de raízes na zona radicular (BERTOL, 1989). O processo de compactação na subsuperfície do solo é comum em preparos convencionais, o que justifica a sua diminuição ou eliminação, passando a adotar-se preparos conservacionistas de solo. A semeadura direta, dentre outras conseqüências, pode ocasionar um aumento da densidade, com consequiente diminuição da macroporosidade na camada superficial, especialmente quando o preparo deixa de ser efetuado por algum tempo.

O sistema de semeadura direta em geral ocasiona um acúmulo de matéria orgânica na camada de $0-5 \mathrm{~cm}$ em relação às camadas subsuperficiais (BAYER \& MIELNICKZUK, 1997; CASTRO FILHO et al., 1998).
O objetivo do trabalho foi quantificar as modificações na densidade do solo, macroporosidade, microporosidade, porosidade total e carbono orgânico, nas camadas 0-2,5, 2,5-5,0, 5,0-10,0 e $10,0-15,0 \mathrm{~cm}$ de profundidade num cambissolo húmico álico, afetadas pela semeadura direta e aração+duas gradagens.

\section{MATERIAL E MÉTODOS}

O trabalho foi conduzido de maio de 1995 a novembro de 1997 no Centro de Ciências Agroveterinárias de Lages (SC), sobre um cambissolo húmico álico argiloso com declividade média de $10 \%$. O solo apresenta $43 \%$ de argila, $10 \%$ de areia, $47 \%$ de silte e $20 \mathrm{~g} \mathrm{~kg}^{-1}$ de carbono orgânico na camada de $0-10 \mathrm{~cm}$ de profundidade.

Os tratamentos, preparo convencional (uma aração+duas gradagens) e semeadura direta (sem preparo do solo), foram instalados em quatro repetições, totalizando oito parcelas com $180 \mathrm{~m}^{2}$ cada uma, num delineamento completamente casualizado. Na semeadura direta, foram cultivadas, em seqüência, aveia, milho, aveia, milho e aveia, tendo sido mantidos todos os resíduos na superfície do solo após a colheita manual do milho e do tombamento da aveia com "rolo-faca". No preparo convencional, a seqüência de cultivos foi aveia, milho, pousio, milho e pousio. Os resíduos do primeiro cultivo de milho foram removidos da área e, do segundo, mantidos. $\mathrm{O}$ preparo do solo, com uma aração+duas gradagens, foi feito imediatamente antes da implantação das culturas de aveia, milho e milho. Em ambos os sistemas de manejo, a aveia foi semeada a lanço, com $150 \mathrm{~kg} \mathrm{ha}^{-1}$ de sementes, e o milho com "saraquá", no espaçamento de $0,9 \mathrm{~m}$ entre linhas e cinco plantas por metro linear.

A sistematização da área experimental foi feita em maio 1995, com a aplicação de calcário, fósforo e potássio incorporados ao solo com uma aração+duas gradagens, de acordo com ROLAS (1995). Foram utilizadas $3,9 \mathrm{Mg} \mathrm{ha}{ }^{-1}$ de calcário dolomítico, $125 \mathrm{~kg} \mathrm{ha}^{-1}$ de superfosfato triplo e $100 \mathrm{~kg} \mathrm{ha}^{-1}$ de cloreto de potássio, iniciando-se em seguida a implantação das culturas recém descritas. Em novembro de 1995 , aplicou-se $250 \mathrm{~kg} \mathrm{ha}^{-1}$ de adubo fórmula 08-18-30, com semeadora "saraquá". Em maio de 1996, a semeadura direta foi adubada com $100 \mathrm{~kg} \mathrm{ha}^{-1}$ de superfosfato triplo, distribuído manualmente a lanço em cobertura no solo e o preparo convencional não foi fertilizado. Em novembro de 1996 , a semeadura direta recebeu $200 \mathrm{~kg} \mathrm{ha}^{-1}$ de fórmula 05-25-25 em cobertura e, no preparo convencional, o fertilizante foi incorporado ao solo pelo preparo. Em maio de 1997, a semeadura direta rece- 
beu $250 \mathrm{~kg} \mathrm{ha}^{-1}$ da fórmula 05-20-10 em cobertura e o preparo convencional não foi fertilizado.

Em novembro de 1997, imediatamente antes da instalação da cultura de verão, foram coletadas amostras indeformadas do solo, utilizando anéis de $5 \mathrm{~cm}$ de altura por $5 \mathrm{~cm}$ de diâmetro, nas profundidades de $0-2,5 ; 2,5-5,0 ; 5-10$ e $10-15 \mathrm{~cm}$, em quatro repetições por tratamento (uma repetição por parcela), para avaliar a macroporosidade, microporosidade e porosidade total em mesa de tensão e a densidade do solo, pela metodologia de FORSYTHE (1975). O carbono orgânico foi determinado em amostras deformadas, com o mesmo número de repetições e nas mesmas profundidades, pela metodologia de TEDESCO et al. (1985).

Os dados foram interpretados utilizandose análise de variância e comparados pelo teste de Duncan a $5 \%$ de probabilidade e por análises de regressão linear e não-linear.

\section{RESULTADOS E DISCUSSÃO}

A densidade do solo foi $12 \%$ maior na semeadura direta do que no preparo convencional, na média das profundidades estudadas (tabela 1). Esse comportamento é explicado pela densidade média $28 \%$ maior nas camadas $0-2,5$ e $2,5-5,0 \mathrm{~cm}$ na semeadura direta, devido à pressão exercida no solo pelas operações de manejo efetuadas durante os cultivos, bem como à consolidação natural do solo em função da ausência de preparo nesse sistema de manejo. Contribuiu para isso o revolvimento do solo efetuado no preparo convencional, que promoveu diminuição da densidade nesse tratamento. Esses dados concordam com FERNANDES $\boldsymbol{e t}$ al. (1983) e VIEIRA (1885), discordando de ELTZ et al. (1989).

$\mathrm{Na}$ semeadura direta, a densidade média das camadas $0-2,5$ e $2,5-5,0 \mathrm{~cm}$ foi $12 \%$ maior do que a média das demais profundidades (tabela 1). Isso mostra que o sistema de semeadura direta promoveu aumento na densidade do solo, com consequiente diminuição na macroporosidade na camada superficial (tabela 2), como demonstram os coeficientes das equações lineares na tabela 3. No entanto, esse aumento na densidade não foi transmitido para as camadas mais profundas, provavelmente em decorrência do espaço de tempo de condução do sistema, ainda insuficiente para tal.

No preparo convencional, a densidade tendeu a aumentar com a profundidade (tabela 1), concordando com dados de FERNANDES $\boldsymbol{e t}$ al. (1983) e VIEIRA (1985). Isso provavelmente é explicado pelas operações de preparo do solo que foram executadas periodicamente nesse sistema de manejo, as quais aumentaram a macroporosidade
Tabela 1 - Valores de densidade do solo (Ds) e carbono orgânico (Co) em diferentes profundidades (Prof), num cambissolo húmico álico submetido à semeadura direta (SDI) e ao preparo convencional (PCO) (média de quatro repetições).

\begin{tabular}{|c|c|c|c|c|}
\hline Prof & SDI & $\mathrm{PCO}$ & SDI & $\mathrm{PCO}$ \\
\hline $\mathrm{cm}$ & \multicolumn{2}{|c|}{--- Ds $\left(\mathrm{kg} \mathrm{dm}^{-3}\right)$---- } & \multicolumn{2}{|c|}{---- $\mathrm{Co}\left(\mathrm{g} \mathrm{kg}^{-1}\right)$} \\
\hline $0-2,5$ & $1,39 \mathrm{a}$ & $1,06 \mathrm{~b}$ & $27,2 \mathrm{a}$ & $22,9 \mathrm{~b}$ \\
\hline $2,5-5,0$ & $1,38 \mathrm{a}$ & $1,11 \mathrm{~b}$ & $22,7 \mathrm{a}$ & $22,8 \mathrm{a}$ \\
\hline $5,0-10,0$ & $1,25 \mathrm{a}$ & $1,24 \mathrm{a}$ & $22,8 \mathrm{a}$ & $22,6 \mathrm{a}$ \\
\hline $10,0-15,0$ & $1,23 \mathrm{a}$ & $1,27 \mathrm{a}$ & $23,4 \mathrm{a}$ & $23,3 \mathrm{a}$ \\
\hline Média & 1,31 & 1,17 & 24,0 & 22,9 \\
\hline $\mathrm{CV}(\%)$ & \multicolumn{2}{|c|}{4,39} & \multicolumn{2}{|c|}{4,70} \\
\hline
\end{tabular}

Para a mesma variável, valores seguidos da mesma letra, na horizontal, não diferem estatisticamente pelo teste de Duncan em nível de $5 \%$ de significância.

(tabela 2) e diminuíram a densidade (tabela 1) na camada superficial, conforme argumentado por BURWELL et al. (1966), acarretando um comportamento inverso dessas variáveis nas camadas mais profundas, em relação à semeadura direta. $\mathrm{O}$ aumento da densidade e diminuição da macroporosidade nas camadas 5,0-10,0 e 10,0-15,0cm foi significativo no preparo convencional, como mostram os coeficientes das equações lineares na tabela 3 .

A macroporosidade na semeadura direta foi equivalente a $43 \%$ daquela no preparo convencional, na média das camadas $0-2,5$ e $2,5-5,0 \mathrm{~cm}$ de profundidade (tabela 2). Isso ocasionou um conseqüente comportamento inverso na microporosidade, nas referidas camadas, podendo ser explicado do

Tabela 2 - Valores de macroporosidade e microporosidade em diferentes profundidades, num cambissolo húmico álico submetido à semeadura direta (SDI) e preparo convencional (PCO) (média de quatro repetições).

\begin{tabular}{|c|c|c|c|c|}
\hline \multirow{2}{*}{$\begin{array}{l}\text { Profun- } \\
\text { didade }\end{array}$} & SDI & $\mathrm{PCO}$ & SDI & $\mathrm{PCO}$ \\
\hline & \multicolumn{2}{|c|}{ Macroporosidade } & \multicolumn{2}{|c|}{ Microporosidade } \\
\hline $\mathrm{cm}$ & \multicolumn{4}{|c|}{$\mathrm{dm}^{3} \mathrm{dm}^{-3}$} \\
\hline $0-2,5$ & $0,13 \mathrm{~b}$ & $0,33 \mathrm{a}$ & $0,44 \mathrm{a}$ & $0,29 \mathrm{~b}$ \\
\hline $2,5-5,0$ & $0,13 \mathrm{~b}$ & $0,28 \mathrm{a}$ & $0,40 \mathrm{a}$ & $0,32 \mathrm{~b}$ \\
\hline $5,0-10,0$ & $0,18 \mathrm{a}$ & $0,09 \mathrm{a}$ & $0,34 \mathrm{~b}$ & $0,42 \mathrm{a}$ \\
\hline $10,0-15,0$ & $0,20 \mathrm{a}$ & $0,06 \mathrm{~b}$ & $0,31 \mathrm{~b}$ & $0,43 \mathrm{a}$ \\
\hline Média & 0,16 & 0,19 & 0,37 & 0,37 \\
\hline $\mathrm{CV}(\%)$ & \multicolumn{2}{|c|}{12,04} & 9,32 & \\
\hline
\end{tabular}

Para a mesma variável, valores seguidos da mesma letra, na horizontal, não diferem estatisticamente pelo teste de Duncan em nível de $5 \%$ de significância. 
Tabela 3 - Parâmetros das equações de regressão linear e não-linear obtidos entre as variáveis densidade do solo (Ds), carbono orgânico (Co), macroporosidade (Ma), microporosidade (Mi), porosidade total determinada (Ptd) e relação macroporos/porosidade total determinada $(\mathrm{Ma} / \mathrm{Ptd})$ e a profundidade, nos sistemas de manejo, semeadura direta e preparo convencional de um cambissolo húmico álico.

\begin{tabular}{|c|c|c|c|c|c|c|c|c|c|c|}
\hline \multirow{2}{*}{$\begin{array}{c}\text { Variá- } \\
\text { vel }\end{array}$} & \multicolumn{5}{|c|}{ Semeadura direta } & \multicolumn{5}{|c|}{ Preparo convencional } \\
\hline & a & $b$ & $b^{2}$ & $r^{2}$ & $\mathrm{Cv}$ & a & $\mathrm{b}$ & $b^{2}$ & $r^{2}$ & $\mathrm{Cv}$ \\
\hline & & & & & $\%$ & & & & & $\%$ \\
\hline Ds & 1,431 & $-0,014$ & - & 0,84 & 2,35 & 1,027 & 0,017 & - & 0,59 & 6,02 \\
\hline $\mathrm{Co}$ & 29,918 & $-1,550$ & 0,075 & 0,54 & 6,09 & 22,737 & 0,021 & - & $0,06^{\mathrm{ns}}$ & 5,49 \\
\hline $\mathrm{Ma}$ & 0,107 & 0,006 & - & 0,87 & 7,33 & 0,376 & $-0,023$ & - & 0,84 & 25,44 \\
\hline $\mathrm{Mi}$ & 0,455 & $-0,010$ & - & 0,60 & 11,19 & 0,263 & 0,012 & - & 0,85 & 7,09 \\
\hline Ptd & 0,562 & $-0,004$ & - & $0,20^{\mathrm{ns}}$ & 7,06 & 0,640 & $-0,010$ & - & 0,71 & 5,98 \\
\hline $\mathrm{Ma} / \mathrm{Ptd}$ & 0,188 & 0,014 & - & 0,81 & 11,14 & 0,612 & $-0,035$ & - & 0,86 & 21,29 \\
\hline
\end{tabular}

ns: Não significativo. (-): inexistente.

mesmo modo como foi feito para a densidade do solo. Esses dados concordam com FERNANDES $\boldsymbol{e t}$ al. (1983) e VIEIRA (1985). A macroporosidade aumentou com a profundidade na semeadura direta $\mathrm{e}$ diminuiu no preparo convencional, com conseqüente comportamento inverso para a microporosidade, como demonstram os coeficientes das equações lineares na tabela 3. Esses dados estão de acordo com aqueles apresentados por VIEIRA (1985).

A porosidade total variou apenas na profundidade $2,5-5,0 \mathrm{~cm}$, entre os sistemas de manejo estudados (tabela 4). Isso mostra que a porosidade total é menos influenciada do que a macro e microporosidade pelo sistema de manejo, já que ela de-

Tabela 4 - Valores de porosidade total determinada (Ptd) e relação macroporos/porosidade total determinada (Ma/Ptd) em diferentes profundidades, num cambissolo húmico álico submetido à semeadura direta (SDI) e ao preparo convencional (PCO) (média de quatro repetições).

\begin{tabular}{|c|c|c|c|c|}
\hline \multirow{2}{*}{$\begin{array}{l}\text { Profun- } \\
\text { didade }\end{array}$} & SDI & $\mathrm{PCO}$ & SDI & $\mathrm{PCO}$ \\
\hline & \multicolumn{2}{|c|}{ Ptd } & \multicolumn{2}{|c|}{$\mathrm{Ma} / \mathrm{Ptd}$} \\
\hline $\mathrm{cm}$ & \multicolumn{2}{|c|}{$\mathrm{dm}^{3} \mathrm{dm}^{-3}$} & \multicolumn{2}{|c|}{$\left(\mathrm{dm}^{3} \mathrm{dm}^{-3}\right)\left(\mathrm{dm}^{3} \mathrm{dm}^{-3}\right)^{-1}$} \\
\hline $0-2,5$ & $0,57 \mathrm{a}$ & $0,62 \mathrm{a}$ & $0,23 \mathrm{~b}$ & $0,53 \mathrm{a}$ \\
\hline $2,5-5,0$ & $0,53 \mathrm{~b}$ & $0,60 \mathrm{a}$ & $0,25 \mathrm{~b}$ & $0,47 \mathrm{a}$ \\
\hline $5,0-10,0$ & $0,52 \mathrm{a}$ & $0,51 \mathrm{a}$ & $0,35 \mathrm{a}$ & $0,18 \mathrm{~b}$ \\
\hline $10,0-15,0$ & $0,51 \mathrm{a}$ & $0,49 \mathrm{a}$ & $0,39 \mathrm{a}$ & $0,12 \mathrm{~b}$ \\
\hline Média & 0,53 & 0,56 & 0,30 & 0,33 \\
\hline $\mathrm{CV}(\%)$ & \multicolumn{2}{|c|}{6,81} & \multicolumn{2}{|c|}{11,13} \\
\hline
\end{tabular}

Para a mesma variável, valores seguidos da mesma letra, na horizontal, não diferem estatisticamente pelo teste de Duncan em nível de 5\% de significância. pende do efeito combinado das duas. Portanto, é mais importante estudar o comportamento relativo da macro e microporosidade com a porosidade total do solo.

A relação macroporos/porosidade total (tabela 4) mostra que a semeadura direta afetou a porosidade de aeração do solo nas camadas 0-2,5 e $2,5-5,0 \mathrm{~cm}$ de profundidade, uma vez que os valores foram, em média, $30 \%$ menores do que os $33 \%$ adequados sugeridos por KIEHL (1979). Isso é conseqüência, provavelmente, do adensamento do solo ocasionado pelo tráfego de máquinas efetuado ao longo do tempo, sem revolvimento do solo. No preparo convencional, por outro lado, a porosidade de aeração foi afetada nas camadas 5,0-10,0 e 10,0$15,0 \mathrm{~cm}$, com valores da relação macroporos/porosidade total cerca de $55 \%$ menores do que o adequado, devido, provavelmente, à pressão mecânica exercida pelos equipamentos de preparo do solo nessa profundidade.

O teor de carbono orgânico foi $19 \%$ maior na semeadura direta do que no preparo convencional, na camada $0-2,5 \mathrm{~cm}$, não diferindo nas demais profundidades (tabela 1). Esse aumento é explicado pela maior quantidade de resíduos vegetais $(2,4$ vezes maior - tabela 5) na semeadura direta, bem como pelo fato desse resíduo ter sido mantido na superfície do solo nesse sistema de manejo e incorporado (misturado) ao solo pelo revolvimento no preparo convencional. O carbono orgânico diminuiu com a profundidade na semeadura direta, enquanto no preparo convencional houve apenas uma tendência de aumento, como demonstram os coeficientes das equações não-lineares na tabela 3. Isso é explicado principalmente pela ausência de revolvimento do solo na semeadura direta e sua presença no prepa 
Tabela 5 - Quantidade de matéria seca produzida pelas culturas, de maio de 1995 a novembro de 1997, adicionada no cambissolo húmico álico submetido à semeadura direta $(\mathrm{SDI})$ e preparo convencional $(\mathrm{PCO})$.

\begin{tabular}{cccc}
\hline Período - Mês/ano & $\begin{array}{c}\text { Tipo de } \\
\text { resíduo }\end{array}$ & $\begin{array}{c}\text { Adicionado } \\
\text { na SDI }\end{array}$ & $\begin{array}{c}\text { Adicionado } \\
\text { no PCO }\end{array}$ \\
\hline & & & \\
& & ------- Mg ha $^{-1}---------$ \\
Novembro/95 & Aveia & 8,1 & 8,1 \\
Maio/96 & Milho & 12,9 & 0,5 \\
Novembro/96 & Aveia & 8,0 & 0,0 \\
Maio/97 & Milho & 10,0 & 10,0 \\
Novembro/97 & Aveia & 6,0 & 0,0 \\
Total & & 45,0 & 18,6 \\
& & & \\
\hline
\end{tabular}

ro convencional, provavelmente influenciando a taxa de decomposição dos resíduos, cujos dados concordam com BAYER \& MIELNICKZUK (1997). Foi influenciado, ainda, pela diferença nas quantidades de resíduos culturais entre os dois sistemas (tabela $5)$.

\section{CONCLUSÃO}

A densidade e microporosidade do solo aumentam na semeadura direta em relação ao preparo convencional, com conseqüente diminuição da macroporosidade, porosidade total e relação macroporos/porosidade total, na profundidade de $0-5,0 \mathrm{~cm}$; na profundidade de $5,0-15,0 \mathrm{~cm}$. No entanto, a microporosidade diminui e a relação macroporos/porosidade total aumenta na semeadura direta em relação ao preparo convencional, e os demais atributos não são afetados.

A densidade e microporosidade diminuem com a profundidade, enquanto a macroporosidade $\mathrm{e}$ relação macroporos/porosidade total aumentam na semeadura direta; no preparo convencional, no entanto, a densidade e microporosidade aumentam com a profundidade, enquanto a macroporosidade, porosidade total e relação macroporos/porosidade total diminuem.

O teor de carbono orgânico diminui com a profundidade na semeadura direta, sendo maior nesse sistema de manejo do que no preparo convencional na profundidade de $0-2,5 \mathrm{~cm}$.

\section{REFERÊNCIAS BIBLIOGRÁFICAS}

BAYER, C., MIELNICKZUK, J. Características químicas do solo afetadas por métodos de preparo e sistemas de cultura.
Revista Brasileira de Ciência do Solo, Campinas, v. 21, p. 105-112, 1997.

BERTOL, I. Degradação física do solo sob a cultura do alho. Agropecuária Catarinense, Florianópolis, v. 2, p. 47-50, 1989.

BERTOL, I., COGO, N.P., LEVIEN, R. Erosão hídrica em diferentes preparos do solo logo após as colheitas de milho e trigo, na presença e ausência dos resíduos culturais. Revista Brasileira de Ciência do Solo, Viçosa, v. 21, p. 409-418, 1997.

BURWELL, R.E., ALLMARAS, R.R., SLONEKER, L.L. Structural alteration of soil surfaces by tillage and rainfall. Journal of Soil and Water Conservation, Ankeny, v. 21, p. 61-63, 1966.

CARPENEDO, V., MIELNICKZUK, J. Estado de agregação e qualidade de agregados de Latossolos Roxos, submetidos a diferentes sistemas de manejo. Revista Brasileira de Ciência do Solo, Campinas, v. 14, p. 99-105, 1990

CASTRO FILHO, C., MUZILli, O., PODANOSCHI A.L. Estabilidade dos agregados e sua relação com o teor de carbono orgânico num latossolo roxo distrófico, em função de sistemas de plantio, rotações de culturas e métodos de preparo das amostras. Revista Brasileira de Ciência de Solo Campinas, v. 22, p. 527-538, 1998

ELTZ, F.L.F., PEIXOTO, R.T.G., JASPER, F. Efeitos de sistemas de preparo do solo nas propriedades físicas e químicas de um latossolo bruno álico. Revista Brasileira de Ciência do Solo, Campinas, v. 13, p. 259-267, 1989.

FERNANDES, B., GALLOWAY, H.M., BRONSON, R.D., et al. Efeito de três sistemas de preparo do solo na densidade aparente, na porosidade total e na distribuição dos poros, em dois solos (Typic Argiaquoll e Typic Hapludalf). Revista Brasileira de Ciência do Solo, Campinas, v. 7, p. 329-333, 1983.

FORSYTHE, W. Fisica de Suelos: Manual de Laboratório. San Jose, IICA, 1975. $212 \mathrm{p}$

KIEHL, E.J. Manual de Edafologia, relação solo-planta. São Paulo: Ceres, 1979. 263 p.

ROLAS - Recomendações de adubação e calagem para os Estados do Rio Grande do Sul e Santa Catarina. Passo Fundo: EMBRAPA-CNPT, 1995. 223 p.

SILVA, I.F. da, MIELNICKZUK, J. Avaliação do estado de agregação do solo afetado pelo uso agrícola. Revista Brasileira de Ciência do Solo, Campinas, v. 21, p. 313-319, 1997.

TEDESCO, M.J., VOLKWEISS, S.J., BOHNEN, H. Análises de solos, plantas e outros materiais. Porto Alegre: Departamento de Solos, Faculdade de Agronomia, UFRGS, 1985. 188 p. (Boletim Técnico, 5).

VIEIRA, M.J. Comportamento físico do solo em plantio direto. In: FANCELLY A.L., (Ed.) Atualização em plantio direto. Campinas: Fundação Cargil, 1985, p. 163-179. 